\title{
Simple Method of 9,10-Anthraquinone Assay in Eleutherine americana (Aubl.) Merr. ex K. Heyne using High-Performance Liquid Chromatography
}

\author{
Sophi Damayanti ${ }^{1 *}$, Samuel Gunadi Tanusondjaja ${ }^{1}$, Benny Permana ${ }^{1}$, Rika Hartati ${ }^{2}$, Dian Ayu Eka \\ Pitaloka ${ }^{3,4}$, and Indra Wibowo ${ }^{5}$
}

${ }^{1}$ Department of Pharmacochemistry, School of Pharmacy, Bandung Institute of Technology,

Jl. Ganesa 10, Bandung 40132, Indonesia

${ }^{2}$ Department of Pharmaceutical Biology, School of Pharmacy, Bandung Institute of Technology,

Jl. Ganesa 10, Bandung 40132, Indonesia

${ }^{3}$ Department of Pharmacology and Clinical Pharmacy, Faculty of Pharmacy, Universitas Padjadjaran, Jl. Raya Bandung-Sumedang KM.21, Sumedang, 45363, Indonesia

${ }^{4}$ Center for Translational Biomarker Research, Universitas Padjadjaran, Jl. Raya Bandung-Sumedang KM.21, Sumedang, 45363, Indonesia

${ }^{5}$ Department of Physiology, Animal Development and Biomedical Science, School of Life Science and Technology, Bandung Institute of Technology, Jl. Ganesa 10, Bandung 40132, Indonesia

\section{* Corresponding author:}

tel: $+62-81394075730$

email: sophi.damayanti@fa.itb.ac.id

Received: March 15, 2021

Accepted: May 3, 2021

DOI: $10.22146 /$ ijc.64701

\begin{abstract}
Eleutherine americana (E. americana) is a medicinal plant commonly found on the island of Borneo, Indonesia. This plant is known to have several biological activities. However, anthraquinone residues are generally present as contaminants. This study was aimed to develop a method of determining the levels of 9,10-anthraquinone in plant extracts and fractions using High Performance Liquid Chromatography (HPLC). The research aims to optimize the mobile phase, the system suitability test, and the system validation. The optimal mobile phase was acetonitrile:distilled water 1:1 v/v with a flow rate of $1.25 \mathrm{~mL} / \mathrm{min}$. The validation result shows that the linearity was obtained with a correlation coefficient ( $r$ ) of 0.9995 and an $r^{2}$ coefficient of 0.9991 . The estimated limits for detection and quantification values were 0.178 and $0.594 \mu \mathrm{g} / \mathrm{mL}$, respectively. In the intraday and inter-day accuracy test, the coefficient of variance for reference was 0.627 and 0.774 , while the results for the sample were 2.966 and 2.658. The percentage recovery rate for reference was between 98.976-101.452\%, and for the sample, the result was 89.191-94.667\%. The average 9,10-anthraquinone content in the acetate fraction of $\mathrm{E}$. americana plant was $9.799 \mu \mathrm{g} / \mathrm{g} \pm 5.243$.
\end{abstract}

Keywords: Eleutherine americana; 9,10-anthraquinone; mobile phase; validation; HPLC

\section{- INTRODUCTION}

Eleutherine americana (E. americana) is a plant in the Iridaceae family group. This plant contains natural compounds that are classified based on the structure into anthraquinones, naphthalene, and naphthoquinones. Several compounds from this group that were found in plants include stigmasterol-3-O- $\beta$-D-glucopyranoside, kadsuric acid, and stigmasterol [1]. Until now, anthraquinone derivatives have been widely studied in various research topics.

Anthraquinone is reported to have antifungal [2] and antimicrobial activity [3]. These compounds belong to the quinone, electrophilic, and other metabolic groups of benzene, phenol, and aromatics, including polycyclics. Anthraquinones have been shown to have a negative property, namely carcinogenicity [4]. However, the risks to airborne organisms, birds, and arthropods 
are considerably low [5]. 9,10-Anthraquinone is a compound that can occur due to the use of pesticides [6]. Therefore, an analysis of this compound is of high importance.

To date, the analysis of compounds in E. americana has been carried out using the thin layer chromatography method. The method was used to observe the antihypertensive activity and lipid profile in hypoestrogenic mice [7]. In addition, anthraquinone analysis is also carried out using Gas ChromatographyMass Spectrometry (GC-MS) and High Performance Liquid Chromatography (HPLC) to determine the analyte as an active compound or contaminant [8-10].

However, hyphenated GC-MS is unfortunately still limited in some laboratories, particularly in Indonesia. Therefore, the HPLC method was developed in this study using various specific eluent compositions (acetonitrilebidistilled water and methanol) to obtain optimal elution of 9,10-anthraquinone. This study aims to develop a validation method for 9,10-anthraquinone in $E$. americana using HPLC. Thus, this study is expected to provide an alternative solvent selection using HPLC to analyze 9,10 -anthraquinone.

\section{EXPERIMENTAL SECTION}

\section{Materials}

Samples (ethanol extract, hexane fraction, water fraction, and ethyl acetate fraction of the bulbs of $E$. americana) were provided by the Biology Pharmaceutical Lab of the Bandung Institute of Technology (Indonesia). 9,10-anthraquinone with a purity of $97 \%$ was purchased from Sigma-Aldrich (St. Louis, MO. USA). HPLC-grade acetonitrile, HPLC-grade Methanol, bidistilled water, and micropore membrane $0.45 \mu \mathrm{m}$ were purchased from Sigma-Aldrich (St. Louis, MO. USA).

\section{Instrumentation}

The instruments used in this research include Waters e2695 High Performance Liquid Chromatography (HPLC), Waters 2489 UV Detector, $4.6 \times 150$ mm ODS3 Inertsil Column, autosampler tube, Hewlett Packard 8453 Diode Array Spectrophotometer, Empower software, sonicator, syringe and filter holder.

\section{Procedures}

\section{Mobile phase development}

Several compositions of the mobile phase were made to obtain the optimum mobile phase for the 9,10anthraquinone analysis. The mobile phase components were previously mixed, filtered with a $0.45 \mu \mathrm{m}$ micropore membrane, and sonicated. The composition of the mobile phases is listed in Table 1.

\section{Preparation of the 9,10-anthraquinone stock solution}

Stock solution with a concentration of $300 \mu \mathrm{g} / \mathrm{mL}$ was prepared from $15 \mathrm{mg}$ of 9,10-anthraquinone and diluted with $40 \mathrm{~mL}$ of the mobile phase. The solution was then stirred, and the volume of the solution was added to $50 \mathrm{~mL}$ with the mobile phase.

\section{Determination of the maximum wavelength absorption of 9,10-anthraquinone}

A solution of 9,10-anthraquinone with a concentration of $6 \mu \mathrm{g} / \mathrm{mL}$ was prepared from stock solutions. Determination of the wavelength with maximum absorption was carried out in the 200-390 nm range using the Hewlett Packard 8453 Diode Array Spectrophotometer.

\section{HPLC system optimization}

HPLC optimization was conducted by determining the flow rate, injection volume, and mobile phase. Afterwards, it was proceeded by calculating several chromatographic parameters, such as relative standard deviation and tailings factor. The system that gave the best results was then selected to be used in this study.

\section{HPLC system}

The HPLC system in this study used an Inertsil ODS-3 $4.6 \times 150 \mathrm{~mm}$ stationary phase, a mobile phase of acetonitrile-bidistilled water (50:50), a UV-Visible detector with a wavelength of $250 \mathrm{~nm}$, a flow rate of $1.25 \mathrm{~mL} / \mathrm{min}$ and injection volume of $10 \mu \mathrm{L}$.

Table 1. Mobile phase composition variance

\begin{tabular}{lc}
\hline Mobile Phase & Composition \\
\hline Bidistilled Water-Methanol & $35: 65$ \\
Acetonitrile-Methanol & $45: 55$ \\
Acetonitrile-Bidistilled Water & $50: 50$ \\
\hline
\end{tabular}




\section{System suitability test}

9,10-Anthraquinone standard solution containing $6 \mu \mathrm{g} / \mathrm{mL}$ was injected into the HPLC by the system mentioned above for 6 replications. The relative standard deviation, tailings factor, column efficiency, capacity factor, and resolution were calculated.

\section{Validation method}

Linearity, limit of detection (LOD), limit of quantification (LOQ). A series of 9,10-anthraquinone standard solutions were prepared from the stock solution using a dilution method in the $1.2-6.0 \mu \mathrm{g} / \mathrm{mL}$ range. The stock solution was diluted to give the concentrations listed in Table 3, with $10 \mathrm{~mL}$ for each solution. Each solution was placed into a different flask and sonicated for $10 \mathrm{~min}$. From each solution, $1 \mathrm{~mL}$ was taken and filtered with a $0.45 \mu \mathrm{m}$ micropore membrane. The solution was then placed into an autosampler, and after that, it was injected into the HPLC. The HPLC response to the injection was then recorded for each concentration (3 replications). Based on the results, a calibration curve was drawn and the regression equation was determined. Furthermore, the correlation coefficients, the LOD and the LOQ values were calculated.

Precision. There were 2 precision tests carried out namely, for the standard solution and for the sample solution. The spiked sample solution was tested using 1.25 $\mathrm{g}$ of the sample added with $1800 \mu \mathrm{L}$ of 9,10-anthraquinone $6 \mu \mathrm{g} / \mathrm{mL}$ working solution. The mobile phase was added to $5 \mathrm{~mL}$ for the standard solution test. The same concentration of the standard solution was added for the spiked sample. For both tests, 6 replications were carried out. Sonication was then performed for both solution groups. For the spike sample solution, $1 \mathrm{~mL}$ of each solution was filtered with a $0.45 \mu \mathrm{m}$ micropore membrane. The solution was then placed in the autosampler for injection. The precision tests that were carried out included the intraday tests and inter-day tests. Accuracy. The accuracy test was carried out on the standard solution and the spiked sample solution. The spiked sample solution was tested using $1.25 \mathrm{~g}$ of sample added with 1440, 1800, and $2160 \mu \mathrm{L}$ of 9,10anthraquinone $6 \mu \mathrm{g} / \mathrm{mL}$ working solution. Each of the 3 samples were then added with the mobile phase to reach a volume of $5 \mathrm{~mL}$. Solutions of the same concentration were also used for the test solution of spiked samples. For both tests, 3 replications were carried out. Sonication was then performed for both solutions. For the spike sample solution, the solution was filtered with a $0.45 \mu \mathrm{m}$ micropore membrane. The solution was then placed in the autosampler for injection.

Sample solution preparation. Ethanol, water, hexane, and ethyl acetate fractions of E. americana were weighed $1.25 \mathrm{~g}$ each, and was then added with the mobile phase to reach a volume of $5 \mathrm{~mL}$. Then $1 \mathrm{~mL}$ was taken from each sample solution and filtered with a $0.45 \mu \mathrm{m}$ micropore membrane, and later placed into an autosampler for injection into the HPLC.

\section{- RESULTS AND DISCUSSION}

The limitations of the laboratory for providing hyphenated chromatography and mass spectrometry are driving research for alternative methods. HPLC has been used to determine 9,10-anthraquinone. In this study, a variety of solvents have been explored. Several combinations of eluent variant compositions have been developed. The details of the new findings are elaborated as follows:

\section{Determination of the Maximum Wavelength Absorption of 9,10-Anthraquinone}

The UV-Visible detector was used in this study to determine the maximum wavelength of 9,10anthraquinone absorption. Based on the research results, the maximum wavelength of 9,10anthraquinone absorption is $250 \mathrm{~nm}$. This result is in line with the study conducted by Dixon [11].

\section{HPLC System Optimization}

The HPLC system optimization aimed to obtain the best chromatogram and find the best elution for 9,10-anthraquinone in the HPLC. Several parameters were used in the research: Inertsil ODS-3 $4.6 \times 150 \mathrm{~mm}$ for the stationary phase, UV-Visible detector, and isocratic elution method. The optimization included the choice of mobile phase and the flow rate. There were 3 combinations of the mobile phase (Table 1). In the 
optimization process, 9,10-anthraquinone standard solution with a concentration of $30 \mu \mathrm{g} / \mathrm{mL}$ was injected.

The first part of the experiment was done with the flow rate of $1 \mathrm{~mL} / \mathrm{min}$, and elution was carried out with the 3 mobile phases. It was found that the retention time was too long using the bidistilled water-methanol (35:65) mobile phase. However, the retention time was too short using the acetonitrile-methanol (45:55) mobile phase. The difference between the retention time of 9,10anthraquinone and the column dead time was only $0.4 \mathrm{sec}$ for acetonitrile-methanol (45:55). The retention time was shorter for the acetonitrile-bidistilled water (50:50) mobile phase compared to the bidistilled water-methanol (35:65). This may be caused by the difference in the polarity strength of the elution of acetonitrile and methanol. Elution by acetonitrile was found to be stronger than methanol [11], and this resulted in the shorter retention time of 9,10-anthraquinone with the acetonitrilebidistilled water (50:50) mobile phase when compared to the bidistilled water-methanol (35:65) mobile phase.

Based on the results, acetonitrile-bidistilled water (50:50) showed the best analysis performance, and therefore it was selected for further research. This result revealed a new composition of solvent to be used in HPLC for the determination of 9,10-anthraquinone. The optimization of flow rate gave $1.25 \mathrm{~mL} / \mathrm{min}$ as the best result. It can be concluded that the HPLC system used in this study were as follows: Inertsil ODS-3 $4.6 \times 150 \mathrm{~mm}$ column, acetonitrile-bidistilled water $(50: 50)$ as the mobile phase, the flow rate of $1.25 \mathrm{~mL} / \mathrm{min}$, isocratic elution method, UV Waters 2489 detector with a wavelength of $250 \mathrm{~nm}$ and an injection volume of $10 \mu \mathrm{L}$.

\section{System Suitability Test}

The system suitability test was carried out by injecting a standard solution of 9,10-anthraquinone with a concentration of $6 \mu \mathrm{g} / \mathrm{mL}$ into the HPLC 6 times. The parameters analyzed included relative standard deviation, tailings factor, resolution, column efficiency, and capacity factor resulting from the system suitability test (Table 2). Based on these results, all tested parameters have met the requirements. Therefore, the optimized HPLC system can be used for method validation.

\section{Method Validation}

The parameters for the analysis of the method validation consist of selectivity, linearity, intraday precision test, inter-day precision test, and accuracy test [12-14]. The selectivity test included comparing the chromatogram of the standard solution and the chromatogram of various samples. Two compounds were retained in the range of 9,10-anthraquinone's retention time in the ethanol extract of E. americana (Fig. 1).

The results showed that this method was not selective for 9,10-anthraquinone in the ethanol extract of E. americana due to the presence of other compounds in the retention time range. The ethyl acetate fraction of $E$. americana showed no other peaks disturbing the 9,10anthraquinone peak. This implies that the method is already selective [12-14]. Based on these results, it can be concluded that the HPLC system is selective against 9,10-anthraquinone in the ethyl acetate fraction of $E$. americana.

The linearity test was carried out by determining the response of the instrument three times to 5 different standard solutions of 9,10 anthraquinones with different concentrations. Based on the calibration curve (Table 2, Fig. 2), the equation $y=18456 x+109415$ was obtained. The minimum acceptable correlation coefficient value

Table 2. System suitability result

\begin{tabular}{lcc}
\hline System Suitability Test Parameters & Result & Requirement [12-14] \\
\hline Relative Standard Deviation for AUC & $0.4 \%$ & $\leq 2 \%$ \\
Relative Standard Deviation for Retention Time & $0.3 \%$ & $\leq 2 \%$ \\
Tailing Factor & 1.39 & $\leq 2$ \\
Resolution & 5.823 & $\geq 1.5$ \\
Column Efficiency & 8113 & $>2000$ \\
Capacity Factor & 4.999 & $1<\mathrm{k}^{\prime}<10$ \\
\hline
\end{tabular}



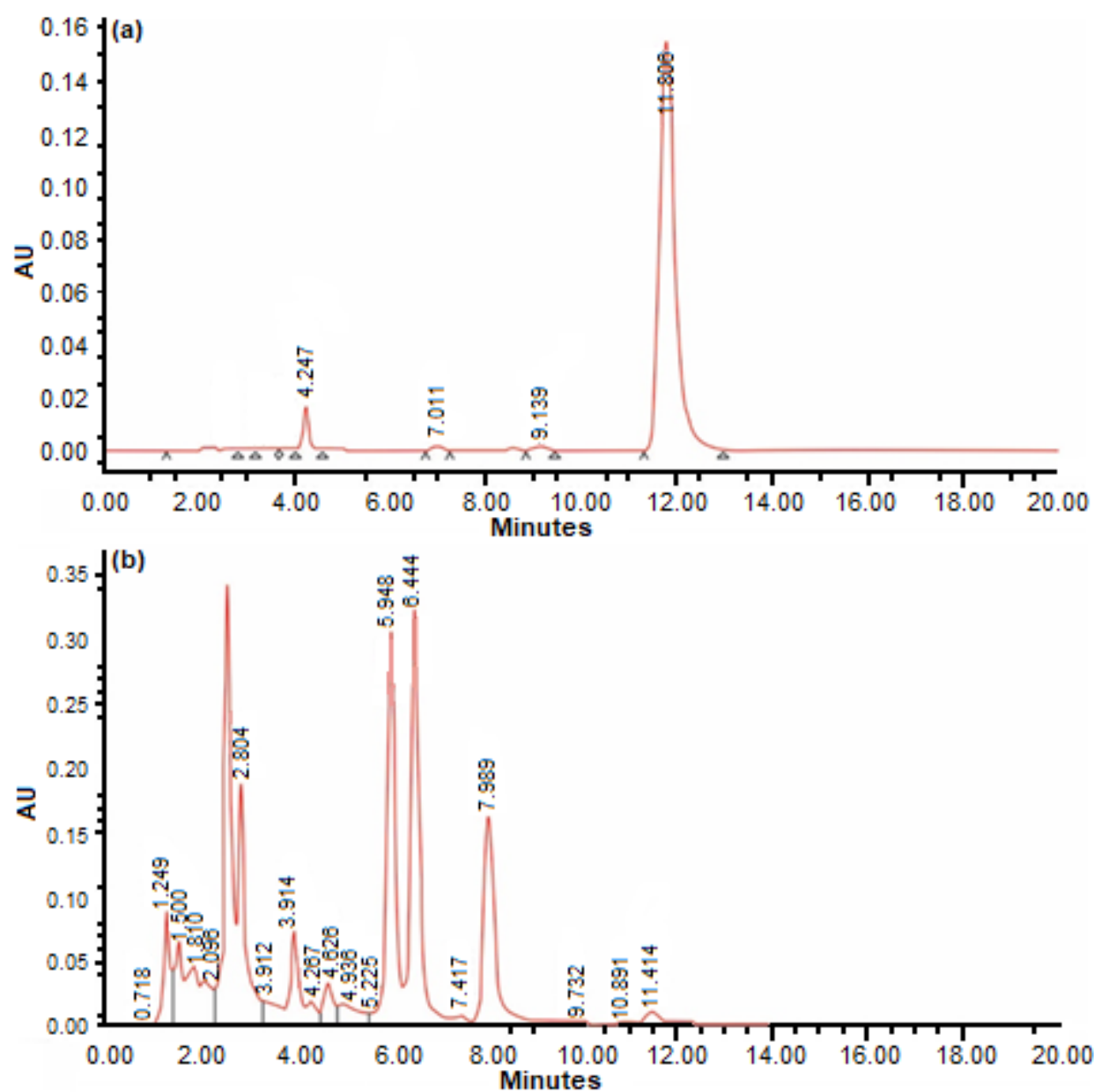

Fig 1. Comparison of the standard 9,10-anthraquinone solution (a) and ethyl acetate fraction of E. americana bulbs (b)

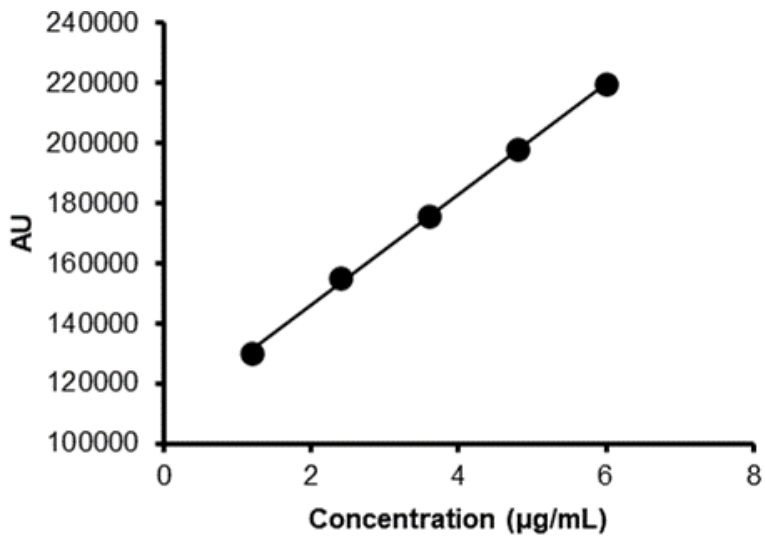

Fig 2. Calibration curve of Standard 9,10-anthraquinone solution $\left(y=18456 x+109415, r=0.9995, r^{2}=0.9991\right)$

was 0.9914 . The value of the correlation coefficient (r) based on the calibration curve was 0.9995 , and the coefficient of determination $\left(\mathrm{r}^{2}\right)$ was 0.9991 . The Vxo value can also be used to determine linearity. Curves can have a very good Vxo value if they are below 5\% [12-14]. In the experiment, the Vxo value was $1.779 \%$. Based on the 2 parameters above, it can be concluded that the calibration curve has met the requirements. Estimated LOD and LOQ were calculated by a calibration curve, using standard deviation, which is the square root of each concentration variant [12-14]. Based on the calibration curve, the estimated LOD value is $0.178 \mu \mathrm{g} / \mathrm{mL}$, and the LOQ is $0.594 \mu \mathrm{g} / \mathrm{mL}$.

The precision test was carried out for the standard solution and the spiked sample solution. The precision of the analytical procedure reveals the closeness of agreement (degree of scattering) between a series of measurements obtained from multiple sampling of the same homogeneous sample under defined conditions [141]. In the accuracy test, 6 response instruments were recorded twice a day (intraday) and on 2 different days (inter-day). 
Table 3. Result of spiked sample solution precision test

\begin{tabular}{cccc}
\hline Precision test & Period & Spiked sample solution $^{\mathrm{a}}$ & $\% \mathrm{CV}^{\mathrm{b}}$ \\
\hline \multirow{2}{*}{ Intraday } & Time 1 & $3.473 \pm 1.998$ & 2.966 \\
& Time 2 & $3.783 \pm 3.934$ & \\
\multirow{3}{*}{ Inter-day } & Day 1 & $3.473 \pm 1.998$ & 2.658 \\
& Day 2 & $2.837 \pm 3.317$ & \\
\hline
\end{tabular}

Notes: (a) Average of the concentration $(\mu \mathrm{g} / \mathrm{mL}) \pm \mathrm{RSD}(\%) ; \mathrm{n}=6$

(b) Average of the RSD (\%)

Precision can be determined by assessing the relative standard deviation (RSD). The RSD value for the 9,10anthraquinone concentration in the sample should be equal to or less than $4 \%$ [12-14].

Based on the experiment, RSD values of the intraday test for the spiked sample solution were $1.998 \%$ and $3.934 \%$, and for the inter-day test, the values were $1.998 \%$ and $3.317 \%$ (Table 4 ). In the standard solution, the intraday test's RSD values were $0.56 \%$ and $0.693 \%$, as for the interday test, the values were $0.56 \%$ and $0.988 \%$. The result for the 2 precision tests already fulfilled the requirement stated by AOAC.

The accuracy of an analytical procedure expresses the closeness of agreement between the value received, as either an actual conventional value or the reference value, and the value found [12-14]. The accuracy test was carried out for the standard solution and spiked sample solution. The accuracy test began with standard addition to the sample at concentrations of $80 \%, 100 \%$ and $120 \%$ based on the sample content [12-14]. The accuracy test was also carried out on the standard solution with the same concentration added to the spiked sample solution. For each concentration, the test was carried out 3 times. The results of the accuracy test are shown as percent recovery. The results of the accuracy test are shown in Table 5.

The \% recovery rate should be between $85-110 \%$ [14]. Based on the results, the recovery value of the spiked sample solution was 89.191-94.667\%, and for the standard solution the recovery value was 98.976$101.452 \%$. This result meets the requirement stated by AOAC.

The validation results show that the method can be applied to the sample. This study can be used as an alternative to the 9,10-anthraquinone analysis that has been developed by other researchers [15-17].

\section{Analytical Method Assay for the Samples}

After the validation parameters are met, the next research stage was to test the sample using HPLC. Ethanol, water, hexane, and ethyl acetate fractions of $E$. americana bulbs were weighed, placed into several containers, and added to the mobile phase. Sonication was carried out to increase the solubility of 9,10anthraquinone in the solvent. After sonication, two filtrations were carried out. Filtration aimed to prevent particles that could damage the HPLC column. In this study, the anthraquinone peaks were between 11.4 and 11.6 min after the HPLC response was obtained. The

Table 4. Result of standard solution precision test

\begin{tabular}{cccc}
\hline Precision test & Period & Standard Solution $^{\mathrm{a}}$ & $\% \mathrm{CV}^{\mathrm{b}}$ \\
\hline \multirow{2}{*}{ Intraday } & Time 1 & $1.354 \pm 0.56$ & 2.966 \\
& Time 2 & $1.745 \pm 0.693$ & \\
Inter-day & Day 1 & $3.473 \pm 1.998$ & 2.658 \\
& Day 2 & $2.837 \pm 3.317$ & \\
\hline
\end{tabular}

Notes: (a) Average of the concentration $(\mu \mathrm{g} / \mathrm{mL}) \pm \mathrm{RSD}(\%)$; $\mathrm{n}=6$ (b) Average of the RSD (\%)

Table 5. Result of accuracy test

\begin{tabular}{ccccc}
\hline $\begin{array}{c}\text { Concentration } \\
(\%)\end{array}$ & $\begin{array}{c}\text { Spiked sample } \\
\text { solution }^{\mathrm{a}}\end{array}$ & $\begin{array}{c}\text { \% Recovery for spiked } \\
\text { sample solution }^{\mathrm{b}}\end{array}$ & $\begin{array}{c}\text { Standard } \\
\text { solution }^{\mathrm{a}}\end{array}$ & $\begin{array}{c}\text { \% Recovery for } \\
\text { standard solution }^{\mathrm{b}}\end{array}$ \\
\hline 80 & $3.635 \pm 1.109$ & $89.191 \pm 3.401$ & $1.346 \pm 1.067$ & $101.167 \pm 1.067$ \\
100 & $3.964 \pm 2.433$ & $94.667 \pm 6.368$ & $1.584 \pm 1.498$ & $98.976 \pm 1.498$ \\
120 & $4.208 \pm 1.454$ & $91.629 \pm 3.479$ & $1.948 \pm 0.683$ & $101.452 \pm 0.683$ \\
\hline \multicolumn{2}{l}{ Notes: (a) Average of the concentration $(\mu \mathrm{g} / \mathrm{mL})+\mathrm{RSD}(\%) ; \mathrm{n}=3$ (b) Average of the \% Recovery (\%) \pm RSD (\%) }
\end{tabular}


Table 6. The amount of 9,10-anthraquinone in the ethyl acetate fraction of the bulbs of E. americana

\begin{tabular}{cc}
\hline Assay & Content $(\mu \mathrm{g} / \mathrm{g})$ \\
\hline 1 & 9.207 \\
2 & 10.068 \\
3 & 10.123 \\
Average of Assay $(\mu \mathrm{g} / \mathrm{g})$ & 9.799 \\
RSD (\%) & 5.243 \\
\hline
\end{tabular}

results were then entered into a calibration curve.

Testing of hexane and water fractions of $E$. americana bulbs showed no trace of 9,10-anthraquinone. 9,10-Anthraquinone may not be detected in this fraction because hexane is a non-polar solvent, whereas water is a polar solvent. Thus, 9,10-anthraquinone as a semi-polar compound was not detected. In the ethanol extract of $E$. americana, there were overlapping peaks in the range of anthraquinone retention times. Therefore, 9,10anthraquinones could not be determined, because the separation of the detected compounds was not yet complete. However, the ethyl acetate fraction of $E$. americana bulbs was found to contain 9,10 anthraquinone (Table 6).

9,10-Anthraquinone obtained from the sample did not meet the requirement set by EFSA in 2012 in which the amount of 9,10-anthraquinone in the sample must be less than $0.01 \mathrm{mg} / \mathrm{kg}$. This requirement may be intended for all residue of pesticides, not specifically for 9,10anthraquinone. The specific requirement for 9,10anthraquinone has not been stated until today. However, the anthraquinon analysis should be determined and the toxicity of anthraquinon should be avoided [18-20].

\section{- CONCLUSION}

The analytical method development for 9,10anthraquinone from the bulbs of E. americana was done by using HPLC with the system of Inertsil ODS-3 $4.6 \times$ $150 \mathrm{~mm}$ column, acetonitrile-bidistilled water (50:50), flow rate of $1.25 \mathrm{~mL} / \mathrm{min}$, isocratic elution method, UVVisible detector with the wavelength of $250 \mathrm{~nm}$, and injection volume of $10 \mu \mathrm{L}$. This method resulted in 9,10anthraquinone peaks at 11.4-11.6 min.

The developed method already fulfilled all requirements for the system suitability test and method validation. In the sample, there was no 9,10anthraquinone in the hexane and water fraction of the bulbs of E. americana but it was detected in the ethanol extract of the bulbs of E. americana, even though it was not separated. The 9,10-anthraquinone content in the ethyl acetate fraction of the bulbs of E. americana was $9.799 \mu \mathrm{g} / \mathrm{g} \pm 5.243$.

\section{- ACKNOWLEDGMENTS}

The research was funded by the Ministry of Research, Technology and Higher Education PDUPT 2017-2018.

\section{- REFERENCES}

[1] Insanu, M., Kusmardiyani, S., and Hartati, R., 2014, Recent studies on phytochemicals and pharmacological effects of Eleutherine americana Merr., Procedia Chem., 13, 221-228.

[2] Kuntorini, E.M., and Misrina, M.D., 2016, Anatomical structure and antioxidant activity of red bulb plant (Eleutherine americana) on different plant age, Biodiversitas, 17 (1), 229-233.

[3] Malmir, M., Serrano, R., and Silva, O., 2017, "Anthraquinones as potential antimicrobial agentsA review" in Antimicrobial Research: Novel Bioknowledge and Educational Programs, Eds. Mendez-Vilas, A., Formatex Research Center, Badajoz, Spain, 55-61.

[4] Yusiasih, R., Pitoi, M.M., Ariyani, M., Koesmawati, T.A., and Maulana, H., 2019, Anthraquinone in Indonesia infusion tea: analysis by HPLC-UV and risk assessment, Chem. Biol. Technol. Agric., 6, 19.

[5] European Food Safety Authority, 2012, Reasoned opinion on the review of existing maximum residue levels (MRLs) for anthraquinone according to article 12 of regulation (EC) No 396/2005, EFSA J., 10 (6), 2761.

[6] DeLiberto, S.T., and Werner, S.J., 2016, Review on anthraquinone for pest management and agricultural crop protection, Pest. Manage. Sci., 72 (10), 1813-1825.

[7] Bahtiar, A., and Chumala, D.Y., 2018, Dayak onions (Eleutherine bulbosa (Mill.) Urb.) bulbs extracts 
reduces blood pressure of hypoestrogen model rats by controlling lipids profile, Int. J. Morphol., 36 (3), 1016-1021.

[8] Rani, V.S., and Nair, B.R., 2015, Pharmacognostic and physiochemical evaluation of bulbs of Eleutherine bulbosa (Miller) urban, a medicinal plant, J. Pharmacogn. Phytochem., 4 (3), 273-277.

[9] Paramapojn, S., Ganzera, M., Gritsanapan, W., and Stuppner, H., 2008, Analysis of naphthoquinone derivatives in the Asian medicinal plant Eleutherine americana by RP-HPLC and LC-MS, J. Pharm. Biomed. Anal., 47 (4), 990-993.

[10] Kumar, R.B., 2017, Application of HPLC and ESI-MS techniques in the analysis of phenolic acids and flavonoids from green leafy vegetables (GLVs), $J$. Pharm. Anal., 7 (6), 349-364.

[11] Dixon, J.M., Taniguchi, M., and Lindsey, J.S., 2005, PhotochemCAD 2: A refined program with accompanying spectral databases for photochemical calculations, Photochem. Photobiol., 81, 212-213.

[12] Suresh, R., Anarthanan, S.V.J., Manavalan, R., and Valliappan, K., 2010, Aspects of validation in HPLC method development for pharmaceutical analysiscomparison of validation requirements by FDA, USP, and ICH, Int. J. Pharm. Sci. Res., 1 (12), 123132.

[13] AOAC International, 2002, AOAC Guidelines for Single Laboratory Validation of Chemical Methods for Dietary Supplements and Botanicals, AOAC International, Arlington, Virginia, US.

[14] Analytical Laboratory Accreditation Criteria (ALACC), 2017, AOAC International Guidelines for Laboratories Performing Microbiological and
Chemical Analyses of Food, Dietary Supplements and Pharmaceuticals: An Aid to Interpretation of ISO/IEC 17025, AOAC International, Rockville, Maryland, US.

[15] Hemmateenejad, B., Shamsipur, M., Safavi, A., Sharghi, H., and Amiri, A.A., 2008, Reversed-phase high performance liquid chromatography (RPHPLC) characteristics of some 9,10-anthraquinone derivatives using binary acetonitrile-water mixtures as mobile phase, Talanta, 77 (1), 351-359.

[16] Xu, L., Chan, C.O., Lau, C.C., Yu, Z., Mok, D.K.W., and Chen, S., 2012, Simultaneous determination of eight anthraquinones in Semen Cassiae by HPLCDAD, Phytochem. Anal., 23 (2), 110-116.

[17] Wei, S.Y., Yao, W.X., Ji, W.Y., Wei, J.Q., and Peng, S.Q., 2013, Qualitative and quantitative analysis of anthraquinones in rhubarbs by high performance liquid chromatography with diode array detector and mass spectrometry, Food Chem., 141 (3), 17101715.

[18] IARC, 2013, IARC Monographs on the evaluation of carcinogenic risks to humans, Volume 101, Some Chemicals Present in Industrial and Consumer Products, Food and Drinking-water, International Agency for Research on Cancer, Lyon, France.

[19] Duval, J., Pecher, V., Poujol, M., and Lesellier, E., 2016, Research advances for the extraction, analysis and uses of anthraquinones: A review, Ind. Crops Prod., 94, 812-833.

[20] Shukla, V., Asthana, S., Gupta, P.K., Dwivedi, P.D., Tripathi, A., and Das, M., 2017, Toxicity of naturally occurring anthraquinones, $A d v$. Mol. Toxicol., 11, 1-50. 